\title{
PRÁCTICAS SOCIALES Y POLÍTICAS AUTÓNOMASY EMERGENCIA DE NUEVOS ACTORES EN LIMA METROPOLITANA: 2014-2017
}

\author{
José MARTÍNEZ LLAQUE \\ Universidad Ricardo Palma \\ jmartinez@urp.edu.pe
}

\section{INTRODUCCIÓN}

Desde los inicios del presente siglo hasta la actualidad, en América Latina y en particular en el Perú, diversos sectores sociales vienen desarrollando un conjunto de movilizaciones y protestas sociales que revisten una nueva orientación política frente al poder del Estado y al poder fáctico. Nos estamos refiriendo a la lucha que vienen librando en este periodo histórico las poblaciones andinas y amazónicas, tales como fueron los casos emblemáticos de Bagua y Conga, y de los sectores urbanos a nivel nacional principalmente de Lima Metropolitana, Arequipa, La Libertad, Cuzco, Huancayo, entre otras. A nivel urbano, las respuestas populares tienen un carácter autónomo no partidario y las movilizaciones se caracterizan por estar integradas mayoritariamente por jóvenes, entre los 18 a 25 años. Y, otro sector de la población por encima de los 30 años. Sus acciones, desde el umbral de la política no partidarizada, son una expresión de reivindicaciones sociales y políticas frente a medidas tomadas por el Estado. Las reivindicaciones están relacionadas con un conjunto de derechos ciudadanos. En Lima Metropolitana, tenemos la emergencia de nuevos actores urbanos, mayoritariamente jóvenes, que se movilizan y, defendiendo sus intereses inmediatos; $y$ al mismo tiempo buscando una identidad política autónoma.

\section{PALABRAS CLAVE}

Acciones colectivas, políticas autónomas, nuevos actores sociales, Perú.

\section{AUTONOMOUS SOCIAL AND POLITICAL PRACTICES AND EMERGEN- CE OF NEW ACTORS IN METROPOLITAN LIMA: 2014-2017}

\begin{abstract}
From the beginning of the present century up to the current importance, in Latin America and in particular in Peru, various social sectors have been developing a set of social the mass demonstrations and protests that have a new political orientation against the of state power and the factual power. We are referring to the struggle that the Andean and Amazonian populations have been waging in this historical period, as were the emblematic cases of Bagua and Conga, and of urban sectors at the national level, mainly in Lima Metropolitana, Arequipa, La Libertad, Cuzco, Huancayo, among other. At the urban level, popular responses have an autonomous, non partisan character and the mobilizations are characterized by being mostly young people, between 18 and 25 years old. And, another sector of the population over 30 years. Their actions, from the threshold that they don't have followers to some political party, are an expression of concrete social and political demands against measures taken by
\end{abstract}


the State. The claims are related to a set of citizen rights. In Lima Metropolitana, we have the emergence of new urban actors, mostly young, who are mobilized that affect their immediate interests; but at the same time they are in search of an autonomous political identity.

\section{KEY WORDS}

Collective actions, autonomous policies, new social actors, Peru.

Recibido: $10 / 8 / 2017$

Aprobado: 15/10/2017 


\section{Interrogantes iniciales ${ }^{1}$}

Desde los inicios de la década de 1950 hasta mediados de la década de 1980 del siglo pasado, diversos procesos económicos, sociales, políticos y culturales desarrollados a nivel global, regional y local modificaron sustancialmente a nuestro país que transitó velozmente de un país rural a un país predominantemente urbano. Según CEPLAN el $85 \%$ de la población del Perú vivirá en ciudades en el año 2050 así como el 70\% de la población del mundo. Lo que venía ocurriendo, tal como lo sostiene Aníbal Quijano en sus reflexiones sobre la urbanización en América Latina, el fenómeno estaba en curso en América Latina, y en el Perú en particular; un proceso de urbanización de la sociedad como expresión de la nueva forma hegemónica de acumulación y expansión del capital a nivel de toda la sociedad. Este proceso de acumulación urbano industrial, hizo entrar en crisis a las estructuras agrarias tradicionales y al proceso migratorio masivo de la población del campo hacia el litoral, especialmente a Lima y Callao, en un principio; y posteriormente a las ciudades intermedias a nivel nacional.

Todos estos procesos van a modificar la estructura de clases, el tipo de Estado así como las distintas expresiones culturales, ideológicas y políticas en el Perú. Estos procesos van a corresponder a dos formas hegemónicas de acumulación de capital. La primera, desde fines de la década del 50 hasta mediados de la década de los 80, una acumulación urbano industrial con la expansión de la urbanización dependiente, la emergencia de un proletariado industrial, nuevas capas medias y sectores populares con demandas que se van a expresar, como José Matos (1984) llamó, un "desborde popular". En esta época, se aperturó un periodo de un vertiginoso ascenso del movimiento obrero y popular y el desarrollo de sus intermediaciones sociales y políticas, democráticas, populares y socialistas (1970-1983).

Este periodo histórico, para algunos representantes de las ciencias sociales no ha sido lo suficientemente estudiado desde el punto de vista del pensamiento crítico. Nos referimos como ejemplos, a la experiencia histórica de la comunidad autogestionaria de Villa El Salvador que prometía ser un modelo para los explotados y oprimidos no solo del Perú sino de Latinoamérica. El otro caso, las experiencias de las movilizaciones de la clase obrera y los sectores populares a nivel nacional en las jornadas de los paros nacionales de 1976 y 1977 que fueron interpretados como situaciones prerrevolucionarias. En ambas experiencias primaron las prácticas sociales y políticas autónomas donde los actores, llámese de la clase obrera en ese entonces, rebalsaron a las intermediaciones políticas, llamase partidos de izquierda. Estas luchas, las que se intensificaban cada vez más van a desembocar en la convocatoria a la Asamblea Constituyente y las elecciones generales en 1980. Mientras que en la Asamblea, los sectores populares y las organizaciones de la izquierda socialista obtuvieron un tercio de los votos representantes, en las elecciones generales, los partidos de izquierda, desde la más radical hasta la reformista, al presentarse divididas quedaron reducidas y sin posibilidades de una reconstrucción y relanzamiento unitario a partir de los movimientos de masas y tuvieron que replegarse poco a poco ante la presencia cada vez mayor del Partido Comunista del Perú: Sendero Luminoso.

1 Este artículo es un avance de un trabajo cientíico en proceso de ejecución bajo el Programa del Vicerrectorado de Investigación de la Universidad Ricardo Palma. 
En las elecciones municipales de 1983 el candidato Alfonso Barrantes Lingan, representante de la Izquierda Unida (IU), ganó la Alcaldía de la ciudad de Lima convirtiéndose en el primer Alcalde Socialista de América Latina. Tras un exitoso gobierno local, principalmente por sus medidas a favor de los sectores más desfavorecidos, como fue la gestión del Programa de Leche para los niños pobres y los Comedores Populares. En las elecciones generales de 1985, Barrantes quedó en segundo lugar, bastante lejos del candidato Alán García. Barrantes renunció ir a la segunda vuelta y posibilitó que García Pérez ganara con comodidad. Con este hecho político, las fuerzas de izquierda, el movimiento obrero y popular y la ofensiva de Sendero Luminoso y el triunfo del APRA la izquierda aceleró su proceso de luchas internas y su fragmentación hasta casi desaparecer de la escena política. Son varias las preguntas pendientes de este periodo histórico que vivió el Perú y que no se han debatido suficientemente. ¿Por qué el fracaso de la izquierda en un periodo de ascenso vertiginoso del movimiento obrero y popular? ¿Qué pasó con las prácticas sociales y políticas autónomas en este periodo que se expresaron en el gobierno autogestionario de Villa el Salvador y durante las jornadas de lucha directa de la clase obrera y los sectores populares en los años 1977-80? ¿Qué lecciones se han sacado de ellas como parte de un proceso histórico que proviene desde la Colonia? ¿Será posible la existencia de gobiernos autónomos en nuestro país a nivel local y regional dentro de una concepción de la autonomía nacional?

Con la llegada de Alberto Fujimori al poder en 1990, el neoliberalismo aceleró su penetración en la economía, la sociedad y la política. Desde el primer momento, Fujimori hizo una alianza con las Fuerzas Armadas, el poder fáctico a nivel interno y los grandes representantes del capital. El modelo neoliberal que implantó, luego del autogolpe de 1992, se hizo previa represión y anulación de los derechos que la clase obrera y el pueblo habían conquistado a lo largo de la historia del siglo XX. La emblemática conquista de las 8 horas de trabajo fue anulada, las libertades democráticas conquistadas fueron cortadas y plasmadas mediante un conjunto de Decretos Leyes que promulgó. De modo que desde mediados de la década de 1980 hasta la actualidad nuestra sociedad y América Latina están bajo la hegemonía del capitalismo financiero. Esto es, los sectores populares encabezados por la clase obrera hicieron prevalecer sus derechos a través del desarrollo del sindicalismo clasista que adquirió un papel relevante en las conquistas laborales de diversa índole, relacionadas a las condiciones de trabajo, de vida y la solidaridad. En todo este escenario, primó la reciprocidad a nivel social y, la organización de clase a nivel político; en cambio de 1985 hacia adelante otras son las características de la sociedad, la política y el Estado los que van a estar relacionados con el proyecto político e ideológico del neoliberalismo.

El periodo histórico que se ha tomado como referencia en la presente investigación, abarca desde el inicio del presente siglo hasta la actualidad. Con el fin del régimen fujimorista, en noviembre del año 2000 , se inaugura un proceso de transición que posibilitó el retorno de la institucionalidad liberal y la vigencia de las conquistas democráticas que el pueblo había conquistado a lo largo del siglo XX , conquistas que Fujimori las anuló desde el inicio de su primer mandato a fin de terminar con los derechos de los trabajadores e instalar una dictadura que se encargó, desde el primer instante de su gobierno, implantar el modelo neoliberal que se caracterizó por desindustrializar, desdemocratizar y entregar la explotación de los recursos naturales a las grandes empresas y consorcios del capital a 
nivel global. En lo que respecta al presente siglo, Anahí Durand (2013), distingue en el Perú dos grandes grupos de movimientos sociales teniendo en cuenta sus marcos identitarios y la estructura organizativa. El primero, cuya problemática se enfoca en cuestiones sectoriales y económicas identificadas con la izquierda y el sindicalismo, como los docentes, campesinos, médicos etc., y el segundo, que se organiza contra la expansión de la industria extractiva minera y petrolera como son los casos de Cajamarca, Espinar, Islay etc. Ambos grupos expresan un gran malestar por la continuidad de las políticas neoliberales.

Para el caso, la autora en mención parte de la definición operativa de movimiento social que implica constituir una identidad basada en el reconocimiento de intereses compartidos y la definición de estrategias conjuntas a desplegar en la acción colectiva a fin de conseguir los objetivos propuestos. Las emergencias a que nos referimos no pueden inscribirse en ninguna definición que utilice de movimiento social, sino de colectivos que se convocan a través de las redes y se disuelven para convocarse nuevamente y, que están empeñados en la en búsqueda de una identidad.

El gobierno de Alejandro Toledo (2001-2006), es otro escenario social y político que se apertura en nuestro país diferente al vivido durante la dictadura de Alberto Fujimori (1990-2000). El gobierno provisional de Alberto Paniagua (2000-2001), se instaló ante la renuncia, desde el exterior, a la presidencia de la República por Fujimori. Valentín Paniagua que le sucedió por mandato del Congreso de la República se abocó a restablecer algunas reformas democráticas que habían sido liquidadas por la dictadura.

El gobierno autoritario de Alberto Fujimori, durante sus dos etapas, implantó el modelo neoliberal que en su primera fase se caracterizó por un conjunto de privatizaciones de las empresas que estaban controladas por el Estado y, la entrega de los minerales e hidrocarburos a las transnacionales. El caso emblemático fue el centro minero de Yanacocha en el departamento de Cajamarca y, el sometimiento de la población que durante su gestión no le generó ningún conflicto, pero que a fines de la década, por los efectos de la crisis asiática originaron conflictos que posteriormente fueron centralizados con la marcha de los cuatro suyos que fue la estocada más fuerte y el principio del fin de la dictadura. Los gobiernos de Alejandro Toledo (2001-2006), Alan García (2006-2011) y Ollanta Humala (2011-2016), desde el inicio hasta el final siguieron implementado el modelo neoliberal y las políticas recomendadas por el Consenso de Washington. Las gestiones de estos tres gobiernos tuvieron que hacer frente a un conjunto de demandas, generadas fundamentalmente por el modelo. En este periodo histórico asistimos a un auge de la movilización popular que generó conflictos sociales permanentes, por las contradicciones antagónicas entre los intereses de las transnacionales avalados por el Estado y, los intereses de la población a nivel local y regional.

La lucha de la población arequipeña contra los intentos de la privatización del agua y otros servicios públicos durante el gobierno de Alejandro Toledo; la lucha contra la privatización y venta de los territorios y la amenaza contra el entorno natural indujo a la población Amazónica de Bagua durante el gobierno de Alan García a la lucha contra la contaminación del agua igual al movimiento andino de Conga en el departamento de Cajamarca, durante el gobierno de Ollanta Humala. Estas luchas emblemáticas que han dejado grandes lecciones estratégicas para el movimiento popular y el movimiento indígena amazónico y 
andino. Por otro lado, durante este periodo se desarrolla una profunda crisis de legitimación de los gobiernos y del propio Estado. El Perú, y en la mayor parte de los países de la región la democracia, los partidos y la política carecen cada vez más de legitimidad. La corrupción corroe todas las instituciones, la inseguridad y la violencia social son cada vez más crecientes. Los partidos carecen de representatividad. No existe democracia interna, el caudillismo impera y cada vez más se debaten entre la legalidad y la ilegalidad. Asistimos a una profunda crisis de representatividad, a nivel social y política. Para muchos, estamos en una aguda crisis de civilización por la diversidad de crisis de todo tipo originadas especialmente por la forma energética de la acumulación de capital que ha puesto en riesgo la existencia de la especie con el calentamiento global y la contaminación de la biodiversidad. El extractivismo es tal vez, el factor fundamental de la contaminación que ha apostado más por el dinero que por la vida. Todos los gobiernos lo fomentan en América Latina y en el Perú en particular.

Son 25 años de Estado neoliberal que vive el Perú y el saldo es negativo con referencia al desarrollo y el progreso que prometieron los partidos si es que accedían al poder. El pueblo, durante la década de los 90 y lo que va del siglo XXI, les dio la confianza eligiéndolos a Fujimori, Toledo, García y Humala, y, ninguno ha podido lograr el ansiado desarrollo y progreso. Todos estos gobiernos han terminado mal, con porcentajes muy bajos de aprobación. La encargada en desenmascararlos ha sido la propia población. Es cuestión, ver los conflictos que reporta mensualmente la Defensoría del Pueblo para ver que la mayor parte son socio ambientales y contra las privatizaciones de los servicios públicos. La educación, la salud, el agua, el desagüe, la electrificación y los costos de los servicios. La contaminación se ha convertido en la más combatida. Los casos Conga, Bagua, Tía María, los intentos de privatización y el alto costo de los servicios, las relaciones civiles, los derechos democráticos, como las de género, juventudes, libertad civil, afro descendientes, LGT, entre otros, son nuevas acciones colectivas, que van abriendo nuevos horizontes, que buscan una sola direccionalidad que nos permita construir un mundo nuevo.

Durante los años 2014 y 2017 en el Perú, particularmente en Lima Metropolitana, diversos colectivos constituidos mayoritariamente por jóvenes, emprendieron grandes movilizaciones. La marcha de los "pulpines" contra los dispositivos normativos para contratar la fuerza laboral juvenil fue el campanazo del inicio de un conjunto de movilizaciones de diverso tipo. Mujeres esterilizadas, contra la candidatura de Keyko que representaba el continuismo del autoritarismo, la corrupción y el crimen organizado. Colectivos urbanos que se convocan a través de medios audiovisuales y que expresan lo que sienten sin olvidar la reivindicación principal. No están politizados, buscan una identidad. Son emergencias, que aspiran una autonomía como sinónimo de libertad, de independencia frente a los partidos políticos y en búsqueda de una identidad que les permita no encontrarse condicionados por motivos ideológicos, programas u organizaciones construidas de antemano. Más, estarían pensando ver la realidad y hacerse preguntas muy abiertas, provisionales, ir despejándolas, corroborándolas en la práctica y solo poseídos de un horizonte que les permita avanzar y resolver todo autónomamente. 


\section{Imágenes, movilización y referentes políticos}

En el Perú, durante los últimos años del gobierno de Ollanta Humala, se han desarrollado un conjunto de protestas a nivel social y político que hacen presagiar futuros escenarios de una creciente confrontación con las distintas fuerzas políticas y el Estado neoliberales. Se trata de la emergencia de sectores del campo popular, particularmente jóvenes que fluctúan entre los 18 a 35 años aproximadamente y que han realizado distintas movilizaciones en contra del sistema, en distintos campos de la sociedad, la política y la cultura. En sus discursos, generalmente confrontacionales; podemos advertir que están en la búsqueda de una identidad y, la que debería tener la izquierda; el tipo de organización que desean construir. Paradójicamente, estas carencias van junto con un desinterés por la importancia de la teoría, relacionada con América Latina; no aceptando nada del pasado en el campo de la organización y la política. En este sentido, son parte de aquellos que están decepcionados de la política, así como de la democracia y las formas de gobierno.

Las reuniones que tienen son muy concurridas y, en las mismas movilizaciones que llevan a cabo no existen símbolos que permiten identificar simpatías, ejemplos. Mucho menos adhesión por los ideales por los cuales lucharon y que permitan empatar con la gente. Y, no solo en el plano político, en la música, por ejemplo, la nueva trova no les impacta y la música andina no les "llena del todo". Si bien es cierto, que no descartan una organización hay mucha resistencia frente a los partidos políticos existentes. Lo que está más cerca de ellos es el colectivo porque hay menos disputas y no son engorrosos. En la ciudad, la tendencia es que estos colectivos tienden a discutir y practicar lo referente a la ciudadanía, el consenso, el diálogo. Con estos criterios, nos informan voceros de otras generaciones, no van a generar una estrategia para la organización porque su incidencia mayor es lo individual y no lo colectivo. Pero, paradójicamente, son anticapitalistas, liberales, anti sistémicos y expresan sus luchas contra el consumismo, la TV basura, el derrame del petróleo y, todo aquello que "el capitalismo mata". La comunicación les llega al instante, no tienen necesidad de que les cuenten, no ven problemas en los gobiernos "progresistas", lo ven bien. No tienen problema alguno frente al mausoleo senderista; son mestizos, etc. En su gran mayoría, son estudiantes, trabajadores eventuales o quienes trabajan por su cuenta, hay pocos trabajadores. En los colectivos la presencia de la mujer es significativa, las manifestaciones son diferentes y tienden a exaltar algunas figuras como la de Velasco, Arguedas, Túpac Amaru y del Che.

Algunos colectivos urbanos, son embriones de organizaciones que se movilizan a nivel nacional: se trataría de un nuevo movimiento autónomo que está en su etapa germinal. Su participación en las marchas en defensa de la mujer, contra el Tratado del Transpacífico y marcha contra Keyko y, apoyo ante la alternativa "democracia o dictadura"(PPK vs. Keyko) muestran entre otros rasgos la pluralidad de voces en contra de lo existente. Ideológicamente, en algunos casos, pueden visualizarse algunos rasgos de socialismos, el Bien Vivir y la Teología de la Liberación, ideología de los "cristianos comprometidos".

De lo expuesto, surgen algunas interrogantes, a partir de las prácticas sociales y políticas de estos actores que provienen de los distintos espacios de la sociedad del campo popular. Es decir, tales cómo se expresan los actores a partir de sus prácticas sociales y políticas la realidad que viven: ¿estamos frente a la afirmación de una individualidad creativa, innovadora que fue relegada por las opciones sociales hegemónicas desde fines de 
la década de 1950 hasta mediados de 1980 o lo que existe en estas dos últimas es una exacerbación individualista como una de las expresiones de la concepción ideológica del neoliberalismo? O, también, lo que se escucha, ¿por qué estos actores populares no confían en la política, en los partidos y la democracia representativa? ¿Existen alternativas frente a una sociedad fragmentada, informatizada, desinstitucionalizada y de exacerbado individualismo como la que existe actualmente en nuestro país? ¿Por qué surgen esporádicamente respuestas colectivas espontáneas, autónomas, convocadas a través de las redes para protestar sobre un problema específico que afecta a sectores jóvenes de la población? ¿Estarán buscando alguna forma de identidad y de organización autónoma que les permita presionar desde las calles y hacer retroceder al Estado o ser intermediarios frente al mismo, las instituciones de la sociedad civil o aspiran un gobierno local comunitario? ¿Habrá espacio para las opciones comunitarias, la reciprocidad y el autogobierno como alternativa autónoma?

¿Será necesario partir de la realidad y las prácticas sociales y políticas para construir una alternativa autónoma de bases que permita concordar con el movimiento de la realidad? Estas preguntas, particularmente las últimas, deben ser planteadas a los colectivos que están emergiendo en estos tres últimos años y que vienen expresándose en las nuevas protestas colectivas, que se apagan y encienden en distintas coyunturas y, que aún no se sabe qué es lo que buscan. ¿Son protestas permanentes en búsqueda de un nuevo horizonte? Más aún, ¿están interesados en buscar los mecanismos que le permitan articulaciones en distintos niveles desde abajo, a lo largo y ancho del país? ¿Será posible dotarse de formas creativas de una auto organización democrática en los niveles mencionados? Todavía, aún más, ¿será posible pensar a nivel global y actuar a nivel local? Son estas y otras preguntas las que son necesarias plantearse en el intercambio de experiencias y debates que brotan de una realidad distinta en la que vivimos durante las décadas de los 70 y los 80 del siglo XX.

\section{Contenidos históricos y repercusiones actuales en el Perú y América Latina}

La crisis del Estado, de la democracia representativa y de las distintas intermediaciones sociales $y$, políticas se ha agravado en los últimos años, situación que ha permitido, entre otros factores, la emergencia de nuevas actores que a través de sus organizaciones (casos de los amazónicos y los andinos) y de distintos colectivos expresan prácticas sociales y políticas de carácter autónomo. Este fenómeno no es novedad ni en el Perú ni en toda América Latina. A lo largo de la historia, tanto a nivel regional como local, se han desarrollado rebeliones, sublevaciones y experiencias autónomas de diversa índole que han emergido como alternativas al orden social y, político dominantes. Muchas sublevaciones y rebeliones de indígenas, en la época de la Colonia fueron respuestas al orden establecido tales como la rebelión de Túpac Amaru en el siglo XVIII, la toma del poder por los haitianos a inicios del siglo XIX, las gestas anticoloniales y autónomas más relevantes de la historia del Perú y de América. Si fueron derrotadas militar y políticamente no lo fueron a nivel subjetivo; se convirtieron en claros ejemplos para los explotados y oprimidos, particularmente de la juventud de hoy que ven en estos ejemplos, y otros posteriores que se desarrollan en el siglo XX y que continúan hasta ahora con la convicción, de que si es posible 
otro mundo diferente al que vivimos. En América Latina, durante los últimos años del presente siglo se han venido gestando alternativas sociales y políticas, de carácter autónomo con distintos niveles de desarrollo de acuerdo a las especificidades históricas de los países a nivel regional y nacional. En algunos casos, estas prácticas sociales y políticas autónomas, como son los casos de Bolivia y Ecuador, desde los movimientos sociales indígenas lograron derrocar a gobiernos y asumir el poder del Estado. En el caso del Perú, otros casos emblemáticos fueron las luchas emprendidas por los movimientos indígenas de la Amazonía, como el caso de Bagua y, el de los andinos de Conga que hicieron retroceder al Estado y a las transnacionales. En el desarrollo de estas prácticas sociales y políticas autónomas, la influencia del movimiento zapatista fue gravitante por tratarse de la primera experiencia exitosa de un movimiento autónomo en la época del neoliberalismo.

Desde los inicios del presente siglo, se ha abierto un nuevo periodo histórico. El hecho es que, desde mediados de los 70 del siglo pasado asistimos a la profundización cada vez más creciente de una crisis raigal del capitalismo global. Ahora, con la globalización solo existe una libertad plena para los movimientos de las mercancías y, del capital bajo su forma financiera. Este periodo se caracteriza, entre otros factores, por la fragmentación social, la mercantilización de toda la existencia social, el consumismo y la corrupción generalizada de la sociedad, el crecimiento de la desigualdad, la exclusión social, la informalidad, la violencia e inseguridad en proceso permanente de individualismo exacerbado. Más aun, los efectos perversos del neoliberalismo están llevando a las sociedades a un verdadero estado de anomia, inexistencia de ciudadanía, informalidad, corrupción y violencia en todos los órdenes de la vida. Como consecuencia de éstos hechos, asistimos a un proceso permanente de estructuración y desestructuración de la vida social y política, donde los actores principales han rebalsado toda la normatividad e institucionalidad y el individualismo y la "guerra de todos contra todos" se han puesto a la orden del día.

Es dentro de este contexto, que distintos movimientos sociales, colectivos diversos y el movimiento popular en general han venido dando respuestas a nivel mundial y, en América Latina. Desde principios de la década de 1990 se han venido realizando distintas movilizaciones contra la creciente regulación del proceso de modernización y los efectos perversos de la globalización y su expresión neoliberal visualizadas en las políticas del "consenso de Washington", diseñadas por las transnacionales norteamericanas y aplicadas a nivel mundial. Es el factor fundamental de profundización de la crisis de los países de la región. Frente a este panorama desolador, creado por el proyecto ideológico y político del neoliberalismo, los pueblos de América Latina y, de nuestro país se han movilizado y rebelado, impactándole duros golpes a este programa del capital profundamente antipopular. No solamente, han retrocedido sino incluso han derrocado y derrotado en las urnas a gobiernos neoliberales de Bolivia, Brasil, Argentina, Venezuela, Uruguay, Chile y Ecuador. En el Perú, como son los casos de Bagua, Conga, Tía María, entre otros, los gobiernos de Toledo, García y Humala han tenido que derogar leyes o suprimir medidas orientadas a la privatización de los recursos naturales y los servicios públicos. En cuanto los llamados gobiernos "progresistas"o"pos neoliberales", que fueron llevados al poder por grandes movimientos sociales andinos, amazónicos y urbanos, durante la décadas de 1990 hasta fines 
de la primera década del presente siglo, lograron un significativo avance en la disminución de la pobreza, la desigualdad y la exclusión social, así como un mayor acceso a la educación y la salud de la población, entre otros.

Sin embargo, durante estos últimos años se han visto sumidos en contradicciones diversas con sectores de la población que se ven afectados a nivel económico y, social así en los derechos ligados a la democratización social y política y la transición hacia un nuevo tipo de sociedad. En lo que respecta a nuestro país, el neoliberalismo de la década de 1990 se caracterizó por ser básicamente privatizador de las empresas públicas y liquidador de las principales conquistas laborales que lograron el movimiento campesino, obrero y popular. Al inicio del presente siglo, a partir del gobierno de Toledo en el 2001 hasta la actualidad, la característica central del modelo neoliberal es el extractivismo. La afectación a las poblaciones básicamente indígenas de la Amazonía y andinas se ha convertido en la principal contradicción del capital contra las poblaciones donde existen los productos primarios básicamente minería y petróleo. Junto a la entrega de los recursos naturales (básicamente minería, petróleo e hidrocarburos), por parte de los gobiernos de turno, a las transnacionales, se van a dar medidas tendientes a la privatización de los servicios públicos lo que permitirá entrar en contradicción con los sectores sociales populares a nivel urbano.

\section{A modo de reflexiones finales: entre las prácticas sociales, los nuevos actores y el mundo neoliberal actual}

Las prácticas sociales y políticas autónomas de la población en el Perú han sido poco consideradas en el campo de las ciencias sociales. Es decir, no es parte del debate permanente como son otros temas. Somos coyunturalmente parte de una minoría que considera, que si es importante por lo menos para confrontar la hegemonía totalitaria del proyecto político del neoliberalismo que para este programa todo es el mercado y el libre movimiento de capitales y mercancías, de poca e insignificante presencia y rol del Estado y evidentemente de todo lo que significa reciprocidad, autogobierno y sobre todo comunidad. Por otro lado, la autonomía, vista en cualquier campo, principalmente a nivel político es parte inherente a nuestra historia desde la época de la colonia hasta la actualidad. No solo en el Perú sino en toda América Latina y el mundo. Con la crisis del capitalismo mundial, a mediados de la década de 1970, se abrió un periodo histórico que tuvo como características fundamentales, el establecimiento de la hegemonía del capital financiero y el desarrollo vertiginoso de la ciencia y la tecnología, hechos que permitieron el desarrollo exponencial de los mercados, del conocimiento, de la producción, de la cultura, del consumo, del individualismo y la competencia desenfrenada, de las opciones diversas a nivel social, político, ideológico y cultural, de la crisis de paradigmas y la emergencia de una nueva mirada de un mundo que no permitía las permanencias, las tradiciones, los saberes modernos sobre la naturaleza, la sociedad y el pensamiento. Es, dentro de este marco donde "todo lo sólido se desvanece en el aire", tal como lo había señalado Carlos Marx en sus reflexiones sobre la naturaleza y el carácter de la sociedad moderna.

Con la caída del Muro de Berlín en 1989, el desmembramiento de la Unión de Repúblicas Socialistas Soviéticas (URSS) y del socialismo estatista de la Europa del Este terminó una época en la historia del mundo. Dentro de este marco, los intelectuales del sistema 
proclamaron el fin del trabajo, el fin de las utopías y el fin de la historia quedando el campo totalmente para el desenvolvimiento del capitalismo en su fase neoliberal la que es actualmente hegemónica. Bastante se ha debatido sobre las causas de este espectacular vuelco del socialismo y la persistente crisis del capitalismo. Aún no se ha estudiado lo suficientemente las raíces estructurales e históricas del fracaso del socialismo y el significado del estalinismo como causa fundamental no solo de la caída del socialismo sino también frente a la subjetividad y su expresión en todos los órdenes de la vida de la naturaleza, la sociedad y el pensamiento a nivel mundial.

Es dentro de este marco, que es posible entender el porqué de la importancia de la autonomía, su significado y las formas que reviste frente al capitalismo contemporáneo y la crisis de la civilización actual. En el mundo y en nuestro país conviven múltiples culturas, cada una de ellas con su propia racionalidad, muchas de ellas en guerra permanente y en conflictos bélicos y odios que parecieran irreversibles. Ante esta crisis, el sociólogo, francés Alain Touraine, se pregunta, "¿podemos vivir juntos?". El racismo, la xenofobia, la desigualdad, la exclusión, la corrupción y la violencia, se han convertido en los grandes problemas que se viven en el mundo, América Latina y nuestro país. Sobre nuestro tema de investigación, hay escasos trabajos a nivel de las Ciencias Sociales de nuestro país. Nosotros, tratamos de abordar las prácticas sociales y políticas que llevan en su seno el sentimiento profundo, consciente e inconscientemente, de la autonomía como alternativa estratégica para superar los grandes males que recorren el mundo, América Latina y nuestro país donde en los últimos años emergen espontáneamente en el universo andino, amazónico y en los centros urbanos como una alternativa ahora aún débil, que está emergiendo como prácticas sociales y políticas en nuestro país.

En los últimos dos o tres años en el Perú y en Latinoamérica, con expresiones y grados distintos, hay una crisis de representatividad política de los sectores populares que se visualiza en la crisis de las intermediaciones políticas principalmente, en los partidos políticos y en los movimientos sociales. Lo que viene emergiendo se manifiesta en múltiples movilizaciones de jóvenes entre 18 y 35 años, que son convocados por las redes sociales y se concentran en lugares, a horas determinadas y, que crean sus pancartas y consignas en el instante para marchar protestando contra un problema que los afectan a ellos(as) y que están buscando una identidad y que son ajeno(a)s a las organizaciones tradicionales. No se sabe qué buscan, a parte de sus reivindicaciones, qué sentido tienen sus acciones colectivas, hacia dónde se encaminan, cómo desean obtener un espacio en la sociedad, qué alternativas tienen, etc. De hecho este no es un fenómeno solo del Perú sino también de América Latina donde existen ejemplos más desarrollados, como el caso de los estudiantes en Chile que empezaron con reivindicaciones concretas relacionadas a la educación y, ahora están planteando otro tipo de sociedad y "que se vayan todos". Otros, como en Bolivia y Ecuador a nivel indígena y gobiernos pos neoliberales que se sostienen con el apoyo de las masas; que practican la autonomía en la toma de decisiones y, que presionan para arrancarle al Estado reivindicaciones importantes.

Algo parecido también sucedió con el movimiento sin tierra en Brasil, Bagua, Conga, entre otros en el mundo amazónico y andino en el Perú y los "pulpines"en el mundo urbano. Ejemplos concretos que se mantienen. Otros, como colectivos de mujeres, de minorías 
sexuales, derechos humanos, grupos de arte y denuncia a nivel de Lima Metropolitana parecidos al que existen en otros lugares que reivindican la comuna. Proponemos entonces, que en el Perú, durante los últimos años, determinados sectores populares han desarrollado prácticas sociales y políticas de carácter autónomo que implican ser vistos como la movilización poblacional bajo un carácter no partidario pero desde el umbral de la política como una expresión de confrontación al ámbito neo-conservador. De igual manera, observamos que, en Lima Metropolitana, tenemos la emergencia de nuevos actores urbanos, mayoritariamente jóvenes, que se movilizan porque les afectan a sus intereses inmediatos; pero al mismo tiempo están en la búsqueda de una identidad política autónoma. Asimismo, podemos explicar que dichos actores sociales se ubican en los distritos de San Juan de Lurigancho y Villa El Salvador, cuya representación son casos específicos y emblemáticos diferenciados en cuanto a la emergencia de nuevos actores sociales con prácticas sociales y políticas de carácter autónomo, distintos a los que la historia de los movimientos sociales ha venido analizando durante las décadas anteriores.

Desde fines de la década de 1950 se han desarrollado distintas acciones colectivas que se convirtieron en movimientos sociales por abarcar estas acciones a nivel nacional, poseer un mínimo de centralización social y políticas y reivindicaciones de carácter nacional, tal como había sido el movimiento obrero y, la conquista de las ocho horas de trabajo y el movimiento estudiantil por la reforma universitaria durante las dos primeras décadas del siglo pasado. Posteriormente, a los antiguos sectores de obreros y de estudiantes, se va incorporarando un fuerte movimiento campesino que va a poner en jaque el poder de la oligarquía con la toma de tierras a lo largo de casi todos los Andes del sur y centro de nuestro país. Nos ubicamos, en el periodo de la crisis final de la oligarquía en el Perú la que posteriormente recibirá la estocada final con la dación de la Reforma Agraria por el Gral. Juan Velasco Alvarado, la más radical después de la que se dio en Cuba. Sobre el desarrollo de los movimientos sociales, desde sus orígenes hasta la crisis del gobierno de Belaúnde Terry en 1967, el texto que impactó más en la época fue el de Denis Sulmont sobre "El movimiento obrero en el Perú"(1970). El periodo del militarismo en el Perú y la lucha de clases fue muy bien descrito y analizado por Aníbal Quijano. Sobre los documentos de los partidos de la izquierda socialistas (revistas, la que mayor profundidad tuvo fue "Sociedad y Política" bajo la dirección de Aníbal Quijano), textos de Alberto Flores Galindo, Carlos Iván Degregori, Nelson Manrique y otros explican esta época. Con la caída del Muro de Berlín y el desplome de la URSS se va a cerrar un periodo histórico de gran auge del movimiento obrero y popular y, se va a inaugurar otro periodo de crisis de los movimientos y partidos "alternativos" al capitalismo y, a un reflujo del movimiento obrero y popular y todas sus representaciones sociales y políticas a nivel de América Latina y del mundo. La puesta en marcha del proyecto neoliberal de un capitalismo extremo.

Luego, desde principios de la década de 1990 hasta los inicios del nuevo milenio, las luchas y distintas formas de protesta social y política van a emerger para dar respuestas a un mundo globalizado, la crisis de la modernidad y sus impactos en América Latina. La necesidad de luchar por otro mundo es posible, marcará el nuevo horizonte histórico que significó el triunfo de la Revolución Zapatista (1994). Los Foros a nivel mundial serán 
la movilización social y política más avanzada frente a la globalización y la crisis del capitalismo a nivel mundial. Sobre este tema y sus distintas vertientes en la política, en el arte, en el conocimiento, en la necesidad de nuevas miradas desde América Latina, grupos de intelectuales latinoamericanos darán nacimiento a distintos enfoques teóricos, políticos, epistémicos, artísticos, éticos, culturales, y filosóficos como el grupo de intelectuales agrupados en el enfoque integral sobre América Latina y la Colonialidad del Poder, donde nuevamente una de las figuras más representativas es Aníbal Quijano, quien también lo fue anteriormente en los estudios sobre la marginalidad y la dependencia en América Latina. Aparte de Quijano, están Walter Mignolo, Rita Segato, Edgardo Lander, Arturo Escobar, Raúl Zibechi, entre otros. Si hay algo en común en todos ellos, es que comparten:"que otro mundo es posible". Ya no es el capitalismo, ni cualquier otra forma de estatismo, llámese socialista, economía social de mercado u, otro sistema donde prime el valor de cambio por sobre todas las cosas, sino de lo que se trata es, construir una alternativa comunitaria dentro y fuera del capitalismo. Es este nuevo enfoque, "una mirada desde América Latina", que toma como referencia básica la presente investigación.

\section{REFERENCIAS BIBLIOGRÁFICAS}

Adel Mirza, C. (2006). Movimientos sociales y sistemas políticos en América Latina. Buenos Aires: CLACSO Libros.

Bauman, Z. (2003). Modernidad líquida. México: FCE.

Calderón Gutiérrez, F. (Coordinador) (2012). La protesta social en América Latina. Buenos Aires: Siglo XXI. PENUD.

Caraggio, J. L. y Lovis Laville J. (Organizadores)(2014). Reinventar la izquierda en el siglo XXI. Hacia un diálogo norte -sur. Buenos Aires: CLACSO, Universidad Nacional de General Sarmiento.

Castells, M. (2008). Redes de indignación y esperanza. Madrid: Alianza Editorial.

Cenceña, A. E. (Coordinadora)(2008). Los saberes de la emancipación y de la dominación. Buenos Aires: CLACSO Libros.

Degregori, C. I. (2012). La década de la anti política. Lima: IEP.

Delgado, M. (2007). Sociedades movedizas. Paso hacia una antropología de las calles. Barcelona: Anagrama.

Durand, A. (2013). Los movimientos sociales y política en el Perú de hoy. Artículo internet. Octubre.

Durand, F. (2004). El poder incierto. Lima: Editorial del Congreso del Perú.

Flores, D.; Tejada, E.; Salazar, G.; Ego Aguirre, M.; Gonzáles, M.; Caven, O. (2011). Nuevas miradas del Perú contemporáneo. Movimientos sociales, identidades y memoria. Lima: Programa Democracia y Transformación Global.

García Linares, Á. (2008). La protesta plebeya. Acción colectiva e identidad indígena, obrera y popular en Bolivia. Buenos Aires: CLACSO y Prometeo Libros. 
Herramienta (Dossier) (2013). Latencias de nuestra américa. № 53. Buenos Aires.

Hoetmer, R.; Castro, M.; Daza, M.; De Echave, J. y C. Ruiz. (Editores) (2013). Minería y movimientos sociales en el Perú. Programa Democracia y Transformación Global. Lima: Cooper Acción AC Sur.

Holloway, J.; Matamoros, F. y Tischer, S. (Compiladores)(2009). Pensar a contrapelo: movimientos sociales y reflexión crítica. Bajo Tierra. México. D.F.: Ediciones, SSIFO Ediciones.

Lander, E. (Compilador)(2005). La colonialidad del saber: eurocentrismo y ciencias sociales. Buenos Aires: CLACSO. UNESCO.

Lucita, E.; Orchani, F.; Nahuel M., F. y Otros (2015). Ensayos Políticos. Debates en torno al Poder, la organización y la etapa. Buenos Aires: Editorial El Colectivo.

O’Phelan Godoy, S. (2012). Rebeliones anticoloniales Perú y Bolivia 1700-1783. Lima: IEP.

OSAL (Observatorio Social de América Latina) (2014). Medios alternativos y movimientos sociales. Buenos Aires: CLACSO.

Solón, P. (2016). ¿Es posible vivir bien? Reflexiones a Quema Ropa sobre Alternativas Sistémicas. La Paz. Bolivia.

Tejada Sánchez, E. (2009). Movimientos sociales y democracia en el Perú de hoy. Reflexiones a propósito de la gesta de Arequipa. Arequipa: Facultad de Ciencias Histórico Sociales de la Universidad Nacional San Agustín (UNAS). Programa Democracia y Transformación Global.

Yapu, M. (Compilador) (2002). Modernidady pensamiento descolonizador. La Paz:Universidad para la Investigación Estratégica en Bolivia IFEA.

Zemelman, H. (2007) De la historia a la política. La experiencia de América Latina. México. DF:: Siglo XXI. Editores. Universidad de las Naciones Unidas.

Zibechi, R. (2007). Autonomías emancipadoras. América Latina en Movimiento. Lima: Universidad Nacional Mayor de San Marcos. Facultad de Ciencias Sociales. Programa Democracia y Transformación Global.

Zibechi, R. (2015). Descolonizar el pensamiento crítico y las prácticas emancipadoras. Bogotá: Ediciones desde abajo. 